\title{
DISKURSUS INFLUENCER KRISTEN DALAM MISI DAN PENGINJILAN KEPADA NATIVE DIGITAL
}

\author{
Joni Manumpak Parulian Gultom \\ Sekolah Tinggi Teologi REAL \\ E-mail: jonimanumpakgultom@gmail.com
}

\begin{abstract}
ABSTRAK
Kemajuan dunia virtual telah membentuk generasi native digital lepas kontrol, tanpa hambatan dan saling terkoneksi. Dunia tersajikan bebas, tanpa makna dan seperti tanpa Tuhan. Penggunaan teknologi media setiap hari selama tiga jam 14 menit dapat memberikan dampak buruk seperti stress, depresi, dan pergeseran yang besar dalam dunia rohani. Pertanyaannya adalah bagaimana solusi masalah kerohanian native digital di saat gereja dengan segala bentuk praktek pelayanan mereka tidak lagi diminati? Bagaimanakah tindakan Influencer Kristen dalam penjangkauan native digital? Dan Misi dan Penginjilan seperti apa yang dapat dilakukan? Tujuan penelitian ini ; [1\} influencer Kristen berperan maksimal sebagai perpanjangan pelayanan rohani.[2] Penghubung Gereja membawa generasi ini terkoneksi ke dalam gereja lokal. [3] Generasi digital ini diselamatkan. Metode penelitian pendekatan kualitatif dengan pengumpulan data melalui studi literature. Argumen penelitian ini bahwa Influencer Kristen mempunyai peran sangat penting dalam misi dan penginjilan dalam menjangkau Native Digital. Beberapa langkah [1] influencer Kristen memasuki ruang media dalam konten pelayanan rohani. [2] Penggunaan tingkat fleksibilitas tinggi dalam konten misi dan penginjilan. [3] Komunikasi Verbal dan Apologetika Kristen yang berkualitas. Diharapkan lewat penelitian ini (1) Influencer Kristen baru bermunculan dengan konten konten rohani, (2) terjadi pertobatan dan pemulihan diri generasi digital, (3) influencer Kristen terintegrasi dengan gereja lokal.
\end{abstract}

Kata kunci; influencer; gereja; native digital; misi dan penginjilan; rohani

\section{ABSTRACT}

The advancement of the virtual world has formed a generation of Native Digitals who are out of control, unhindered, and connected. The global world is presented freely with negative life values, meaningless and like without God. The use of quiet massive media technology every day for three hours 14 minutes per day can have ungood effects such as stress, depression, even not caring about spirituality. This generation is known to have experienced a major shift in the spiritual world, no longer believing in the existence of God. The question is how to solve the problem of native digital spirituality when churches with all forms of their ministry practices are no longer in demand? How do Christian influencers act in Native Digital outreach? And what kind of Mission and Evangelism can be done? The argument is that Christian influencers have a role and penetration capacity as an answer in missionary actions and evangelism to reach Native Digitals. Several steps of penetration [1] demonstrate the position of Christian influencers as extensions of church ministry in the media space. [2] Maximize mission and evangelism through a high degree of flexibility. [3] 
Preparation for ministry in a deep spiritual capacity. The purpose of this research is so that Christian influencers can play the highest role as spiritual media in Native Digital spiritual missions and outreach. The second thing is to become a liaison for the Church in the virtual world to bring this generation back to being connected to the local Church. Third, bring this generation to be saved. A research method is a qualitative approach with data collection through literature study and observation. It is aimed that through this research (1) new Christian influencers will emerge with spiritual content, (2) conversion and self-recovery of the digital generation will occur, (3) Christian influencers integrated with local churches.

Keywords; influencers; church; native digitals; mission and evangelism; spiritual

\section{PENDAHULUAN}

Dalam dunia digital segala sesuatu menjadi cepat dan akurat. Dari era Industri 4.0 bergerak ke era society 5.0 hampir seluruh aspek kehidupan manusia terintegrasi dalam dunia virtual. Dengan perkembangan teknologi informasi dan media sosial ini maka anak anak milenial dan generasi selanjutnya menjadi generasi Native Digital yaitu generasi yang lahir saat internet telah menjadi bagian integral mereka (Supratman, 2018). Pola kehidupan mereka ini adalah berkomunikasi, berperilaku, bekerja dan berfikir sebagai masyarakat digital. Fenomena-fenomena baru terjadi di kalangan anak milenial, gejala gejala umum serta tipe perilaku dalam penggunaan media sosial dan komunitas anak muda secara digital (Ahmad, 2020). Mulawarman dalam penelitiannya mendapatkan konsep-konsep yang baru dari pengalaman yang bisa muncul secara tiba tiba (Mulawarman \& Nurfitri, 2017). Di Indonesia sendiri jumlah pengguna internet mendekati angka 202 juta jiwa naik $16 \%$ dari tahun 2020 dengan pengguna sosial media sekitar 170 juta jiwa. Profil umur pengguna media sosial di Indonesia yang berumur 18-36 tahun sekitar 64,8\%, dan umur 37 - 44 tahun 13,1\%. Jadi total terdapat $77,9 \%$ dari penduduk Indonesia yang berumur 18-44 tahun adalah pengguna sosial media yang aktif (Kemp, 2021). Dalam bagian lainnya Supratman mengemukakan bahwa ciri generasi Native Digital adalah multitasking, selalu berjejaring, akses secara acak, menyukai permainan yang interaktif, ingin mendapatkan informasi secara cepat dan lebih menyukai informasi pada sumber-sumber online daripada sumber informasi di perpustakaan. Pemberian informasi serta hiburan dalam ruang digital, telah menjawab esensi kebutuhan manusia seperti hobby, kuliner, fashion, teknologi dan lain-lain.

Namun di sisi lainnya dampak buruk telah mencengkram nilai rohani dan kebenaran (Camerling, Lauled, \& Eunike, 2020). Mereka sudah menjadikan ruang media ini seperti agama baru (Rumbiak, 2020). Bahkan menurut Alexandru bagian terburuk 
adalah ketika agama, spiritual hilang; drama manusia yang kehilangan jati diri jiwa dalam identitas kebangsaan, budaya dan pendidikan yang seharusnya. Fenomena ini adalah akibat yang terjadi ketika mereka tidak menerima konten yang benar dan rohani sebagai benteng pertempuran melawan nilai negatif kehidupan dunia digital untuk kembali ke dalam pertumbuhan spiritual dan manusia yang normal (Negoita, 2019).

Globalisasi nilai-nilai dalam dunia digital telah membentuk pola kehidupan baru yang cenderung negatif mempengaruhi native digital. Dengan penggunaan media sosial tiga jam 14 menit setiap hari dapat memberikan dampak buruk seperti stress, depresi, halusinasi, komunikasi terhambat bahkan tidak lagi peduli dengan kerohanian. Generasi ini didapati mengalami pergeseran yang besar dalam dunia rohani, tidak percaya lagi dengan keberadaan Tuhan dalam dirinya(Subowo, 2021). Bila dikaitkan dengan penelitian Bilangan Research Center 2021 yang menyatakan indeks Nasional adalah 3,78 dari skala 5 maka dapat dilihat variable pengalaman rohani anak milenial tentang gambar diri, motivasi dan pengaruh justru kurang dari yang seharusnya (Irawan, 2021). Hal ini menunjukkan bahwa penggunaan media sosial tidak berpengaruh kuat membangun kepada nilai kerohanian, bahkan justru yang terjadi sebaliknya. Permasalahan lainnya meskipun Native digital ini sangat terbuka dengan moral dan spiritual namun dalam prakteknya penuh dengan keragu-raguan. Kehidupan kasih dalam keluarga longgar dan tidak suka dengan well religion organized(Rumbiak, 2020).

Penelitian Garcia di Spanyol telah memberikan istilah baru yaitu Influencer Bacaan untuk memobilisasi minat baca penduduk untuk buku-buku dengan kategori yang berkualitas. Konsep yang digunakan para Influencer bacaan ini dengan pendekatan Partisipasi, Pengalaman, dan Usulan Aturan yang menjadi acuan untuk mendapatkan buku bacaan yang baik dan berkualitas(Garcia-Roca, 2020). Sedangkan di Tiongkok Nancy Yang dan kawan-kawan memberikan hasil penelitian tentang pentingnya Influencer Kesehatan Seksual untuk meyadarkan bahaya yang mengancam dari Tes Mandiri HIV/Sifilis di antara Pria yang berhubungan Seks dengan Pria sebagai media pembelajaran kepada masyarakat luas tentang dampak yang berbahaya dari seks sesama jenis. Pertanyaannya adalah bagaimana solusi permasalahan kerohanian native digital di saat gereja dengan segala bentuk praktek pelayanan mereka tidak lagi diminati? Bagaimanakah strategi dan tindakan Influencer Kristen dalam penjangkauan native digitali ini? dan bentuk Misi dan Penginjilan seperti apa yang dapat dilakukan? 
Penelitian Barna yang terbaru menyatakan bahwa bentuk pelayanan gereja selama 5 dekade terakhir tidak dapat menjangkau native digital. Diperlukan suatu pendekatan dan strategi baru buat mereka. Jawaban dan solusi permasalahan ini menjadi sangat penting dan mendesak sebab kecenderungan gambar diri dan rohani Native Digital telah rusak dan semakin membahayakan masa depan generasi Kristen. Meskipun mereka pintar, kreatif, masih muda, kuat, penuh ide inovasi dan ceria namun mereka juga adalah pribadi yang sangat rapuh, tidak bisa menjaga rahasia sehingga menjadi target penipuan dan sangat tergantung dengan komunitas virtual(Suci Prasasti, 2020). Mereka rentan mengikuti pola dan jati diri global tanpa seleksi. Meskipun ada pelayanan gereja dan kegiatan rohani lainnya tetapi tetap anak milenial ini sangat dipengaruhi dengan nilai yang dibagikan lewat influencer dalam IG, FB, Youtube, Tiktok dan lain lain (Supratman, 2018).

Penulis memberikan argumentasi dalam penelitian ini bahwa para influencer Kristen mempunyai peran dan kapasitas penetrasi yang kuat sebagai jawaban dalam tindakan upaya misi dan penginjilan untuk menjangkau Native Digital yang hampir terhilang ini. Dalam artikel ini penulis memberikan langkah penetrasi influencer Kristen dalam misi dan penjangkauan native digital yang dapat dikategorikan dengan langkah pertama adalah menunjukkan posisi influencer Kristen ini sebagai perpanjangan tangan dari pelayanan gereja dalam ruang media. Hal kedua adalah adalah dengan memaksimalkan misi dan penginjilan influencer dengan mempergunkanan tingkat fleksibilitas tinggi mereka miliki. Dan hal ketiga adalah dengan melakukan persiapan spesial dan khusus tentang metode pelayanan Influencer Kristen dalam kapasitas pelayanan Ilahi yang mendalam.

Tujuan penelitian ini pertama supaya influencer Kristen dapat berperan maksimal sebagai media rohani dalam misi dan penjangkauan rohani Native Digital, sehingga kembali kepada nilai-nilai kebenaran Ilahi yang sesungguhnya. Tujuan kedua adalah menjadi penghubung Gereja dalam dunia virtual untuk membawa generasi ini kembali terhubung dan melayani Tuhan dalam gereja lokal. Tujuan ketiga adalah menunujukkan nilai gambar diri yang benar dan keberhargaan sejati sehingga mereka diselamatkan.

\section{METODE}

Metode yang digunakan adalah kualitatif dengan pengambilan data melalui 
studi pustaka dan fenomenologi. Sonny menyatakan gejala atau fenomena sebagai titik tumpu penelitian, sehingga pengalaman manusia menjadi acuan pengamatan. Agama membawa penganutnya ke dalam pengalaman-pengalaman spiritual. Fenomena dari pengalaman-pengalaman itulah yang menjadi fokus penelitian (Zaluchu, 2020b). Deskripsi ini terdiri dari "siapa" dan "bagaimana fungsi” dari Influencer Kristen. Kemudian penelitian mengungkap kebutuhan rohani dari native digital terhadap perkembangan teknologi media. Selanjutnya penelitian diarahkan dengan memunculkan atau melahirkan influencer Kristen dalam tugas misi dan penginjilan di ruang digital meski hal ini masih dikritisi baik secara positif maupun negatif. Bagian akhir adalah dengan penekanan kapasitas spiritual yang harus dipersiapkan oleh influencer Kristen agar maksimal dalam panggilan pelayanannya di ruang digital. Proses pengumpulan data melalui study pustaka, jurnal dan buku, serta hasil survey dan web, sehingga mendapatkan kajian tentang influencer, Misi dan Penginjilan serta, ruang virtual dengan native digital serta karakter-karakter spesial secara terstuktur.

\section{HASIL DAN PEMBAHASAN}

Perkembangan dunia informasi dan sosial media telah menghubungkan bagian dunia berinteraksi dengan cepat. Bukan saja kepentingan pribadi sehari-hari namun telah menjadi kebutuhan utama dan mendasar dalam pekerjaan, dunia usaha, fashion, pendidikan dan aspek lainnya. Keadaan seperti ini telah membentuk komunitas native digital yang dicetuskan pertama kali oleh Marc Prensky sebagai generasi "penutur asli" dari bahasa digital komputer, video game, dan internet.(Marc Prensky, 2001). Mereka menjadikan dunia virtual sebagai pola dan aktivitas kehidupan tanpa batas ruang, waktu dan umur. Sedangkan influencer artinya adalah seseorang yang memiliki kapasitas untuk mempengaruhi orang lain berkenaan dengan otoritas, pengetahuan, posisi atau berhubungan dengan audiens. Perlu menjadi penekanan tersendiri bahwa influencer bukan hanya berperan dengan pemasaran produk semata namun juga merupakan aset sosial dalam membangun hubungan yang spesial untuk diajak bekerjasama dalam mencapai tujuan tertentu. Bukan saja berperan dalam hal ekonomi namun bahkan juga ideology sampai teologi. Influencer Kristen sendiri menekankan kepada seseorang yang memberikan pengaruh yang berhubungan dengan nilai-nilai kekristenan. Sedangkan Misi dan Penginjilan secara umum terangkum dalam Amanat Agung Tuhan Yesus 
dalam Matius 28:18-20. Amanat Agung tersebut kemudian dimanifestasikan oleh gereja dalam berbagai bentuk misi, program kerja, dan pelayanan. Menurut Lilo gereja seharusnya tidak menutup diri terhadap arus globalisasi, namun konsisten melakukan tindakan Amanat Agung Yesus Kristus. Gereja justru akan menjadi lembaga yang dinamis serta dapat terus bertumbuh dan berkembang. Perkembangannya kali ini tidak hanya berkaitan dengan adanya perubahan arsitektur bangunan, perbaikan kualitas infrastruktur, restrukturisasi organisasi, reformasi doktrin, tetapi juga mencakup upaya gereja memodernisasikan dan atau mengkontekstualisasikan pola pelayanannya di setiap zaman yang berbeda (Lilo, 2020).

\section{Influencer Kristen sebagai Perpanjangan Pelayanan Gereja}

Pelayanan gereja sendiri hari ini telah bertransformasi dari pelayanan tatap muka kepada ruang virtual. Gereja tidak dapat lagi menggunakan strategi tradisional dengan khotbah dan panggung gereja lokal. Kehidupan native digital sendiri telah berada dalam dunia maya dan dunia nyata secara bersamaan(Dwiraharjo, 2020). Tentu diperlukan strategi baru dalam pelayanan gereja sekarang ini. Influencer Rohani dapat menjadi solusi kuat memberi nilai-nilai kebenaran dalam konten media sosial. Mengapa demikian? Menurut editorial musik dunia, pengguna media sosial menggunakan $90 \%$ konten berkaitan dengan musik seperti postingan atau berbagi musik. Plat form yang digunakan bermacam-macam namun 57\% mengikuti setidaknya satu artis atau band, 50\% mengikuti setidaknya satu artis atau aktor (William Glanz, 2018). Dalam disertasinya Hanan Ezzat mendapati bahwa penggemar mengijinkan influencer media memainkan peran dalam kehidupan mereka dengan mendekatkan diri dan memperhatikan apa perkataan mereka. Sehingga hasil akhir hubungan gambar diri yang menyerupai tercipta secara imajiner (Ezzat, 2020). Penelitian Afandi melihat bagaimana nilai-nilai kerohanian secara konservatif dapat diajarkan kepada generasi milenial dalam media virtual (Afandi, 2018). Sedangkan dalam penelitian Diana, komunikasi digital menjadi jawaban untuk mentransferkan nilai rohani untuk komunitas virtual(Diana, 2019). Sedangkan Anjani mendefinisikan bahwa influencer adalah seorang aktivis, yang terhubung dengan baik, berdampak, aktif pikiran, dan trendsetter bagi para pengikutnya. Secara umum influencer media sosial adalah individu yang dianggap sebagai pemimpin opini dalam topik tertentu, baik kecantikan, makanan, fashion, gaya hidup di platform 
media sosial(Anjani \& Irwansyah, 2020). Pengertian yang didapat bahwa Influencer rohani setidaknya harus dikenal dekat dan diikuti oleh native digital dengan aktifitasaktifitas konten spiritual yang menjadi kebutuhan native digital kekinian. Kesemuanya ini di kemas dengan musik atau lagu rohani akan lebih efektif dalam mentransferkan nilai rohani buat mereka.

Melihat kepada perubahan paradigma pelayanan gereja dengan kemajuan teknologi media sosial maka Influencer Kristen menjadi salah satu jawaban penting untuk pelayanan Misi dan Penginjilan kepada native digital(Anjani \& Irwansyah, 2020). Sebuah contoh negara Venezuela, negeri mayoritas pemeluk Katolik telah mengenal influencer rohani bernama Pastor Salazar yang berumur 34 tahun. Dia menggambarkan dirinya sebagai "Influencer Katolik" dengan memposting video rohani dalam Instagram nya sejak tahun 2018. Setiap tahun akun nya selalu mengalami penambahan jumlah dari awalnya sekitar 5000 followers menjadi 120.000 followers.(Manuel Rueda, 2019) Sedangkan di Indonesia telah dikenal influencer Kristen bernama Raditya Oloan yang menjadi salah satu influencer Kristen generasi milenial paling berpengaruh, dimana telah mengubah banyak anak milenial kepada Kristus, namun meninggal dunia karena Covid 19 pada umur 36 tahun. (Toatubun, 2021)

Ada beberapa alasan mengapa Influencer Kristen berposisi sebagai perpanjangan pelayanan Gereja dalam ruang media. Pertama karena sifat gereja yang sangat kaku dan tertinggal dalam kemajuan teknologi. Beberapa kalangan gereja sangat orthodox dan tradisi. Bentuk ibadah yang harus tatap muka dengan tingkat kedisiplinan hadir secara onsite telah menjadi variable ukuran kerohanian seseorang. Hal ini tidak lagi berlaku dalam era kemajuan teknologi media. Gereja harus melakukan strategi berbeda dalam misi dan penjangkauan generasi digital. Dalam penelitian McCorquodale yang meneliti kegerakan Katolik, menyatakan bahwa hingar bingar keberhasilan kemajuan team pastoral dalam era puluhan tahun yang lalu, semua tinggal sejarah. Hanya panggilan untuk evangelisasi dan pendampingan yang diperlukan dengan kerangka bergerak ke arah yang baru.(McCorquodale, 2021) Penelitian Barna pada bulan Agustus 2021, menyatakan meskipun sebagian besar mengatakan gereja mereka telah melakukan pekerjaan yang baik dengan memperlengkapi anak muda native digital untuk berbicara tentang iman (47\% pasti, 39\% mungkin), namun sebagian besar remaja Kristen (68\%) berbagi bahwa mereka tidak pernah memiliki pelatihan khusus untuk 
penginjilan.(McCorquodale, 2021) Hal ini menunjukkan bahwa terjadi gap yang besar dalam penjangkauan jiwa didalam gereja itu sendiri bahkan sesama generasi.

Hal kedua Influencer Kristen menjadi perpanjangan dari pelayanan gereja karena pelayanan gereja sendiri tidak maksimal dalam ruang virtual. Dalam penelitian Sonny hubungan dengan Tuhan tetap manual, tradisional tidak boleh mengikuti bentuk digitalisasi. Teknologi hanya menjadi jembatan bukan sebagai isi (Zaluchu, 2019). Pelayanan virtual menjadi metode penjangkauan dari seluruh organisasi gereja pada masa kini. Gereja telah beradaptasi kedalam penerapan era industry 4.0 kepada era society 5.0 dalam pelayanan jiwa-jiwa namun tetap isi penyampaian harus sesuai dengan makna sesungguhnya. Namun tidak dapat dipungkiri bahwa dunia digital “apriori” kepada konten-konten religious murni. Gereja hadapi penyusutan tingkatan partisipasi aktif komunitas rohani serta kecerdasan spiritual pendalaman keagamaan di golongan native digital. Oleh sebab itu gereja memerlukan influencer-influencer rohani untuk bergerak lewat media. Hal ini sesuai dengan riset Paul yang mengkaitkan komunitas berusia muda dalam beberap tahun terakhir, yang menciptakan pengembangan model pelayanan yang menjawab trend, menjawab permasalahan disaffiliasi serta literasi agama dikalangan generasi digital.(Soukup \& Glader, 2020) Gereja digital bukan lagi menjadi alternative namun telah menjadi solusi mendesak untuk dilaksanakan. Camerling, Lauled, Eunike menyatakan juga pelayanan media adalah untuk kalangan yang belum dan sukar untuk dijangkau secara tatap muka(Camerling et al., 2020). Sehingga penatalayanan baik penggembalaan gereja dalam bentuk persekutuan, kesaksian dan pendalaman Alkitab atau kesaksian, misi dan penginjilan dapat berlangsung secara fleksibel sesuai kebutuhan. Ini melengkapi penelitian Yahya bahwa gereja dan segala bentuk program virtual bukan sekedar ministry namun berkualitas spiritual yang mendunia.(Afandi, 2018). Gereja dapat mengambil kesempatan ini seperti dengan mengutus misonari di ladang-ladang misi, namun dalam dunia digital gereja mengutus influencer-influencer Kristen sebagai misonari digital.

\section{Fleksibilitas: Misi dan Penginjilan Native Digital}

Unsur fleksibilitas ini menjadi unsur penting dari influencer Kristen untuk dapat selalu terhubung dengan generasi ini tanpa merasa kaku dan formal. Kebutuhan tentang 
keselamatan dan kehidupan yang rohani dapat disajikan secara positif dan berkesinambungan dalam casing komunikasi digital native yang sangat kaya dengan inovasi dan kreasi. Segala bentuk penyajian dan pemaparaan kekinian justru dapat memberikan suasana yang berbeda. Namun harus diperhatikan bahwa tanpa persiapan yang matang dan komunikasi unggul dalam misi mewartakan kabar baik maka kehadiran kuasa dan hikmat Tuhan dapat terhambat. Influencer Kristen dapat memberikan pemahaman dan kedalaman nilai Injil dalam ruang publik, virtual dan tanpa batas. Gambar diri Ilahi dipaparkan dengan jelas, mudah dimengerti dan dapat diterima namun tetap berkualitas. Dalam penelitian Amelia Kimberlyann menyebutkan dengan unsur transenden dan imanen dengan peran ortodoksi, ortopraksis dan ortopati yang kuat.(Rumbiak, 2020). Dalam Bahasa misi dan penginjilan adalah Jalan, Kebenaran dan Kehidupan, artinya teologi yang disampaikan Gereja memberikan tanggung jawab pewartaan Injil kepada influencer Kristen dalam dunia media. Mereka menjadi penyambung lidah Allah, "gembala gembala" dalam ruang virtual. Terjadi perpanjangan fungsi Ilahi serta mendatangkan pelayanan gereja yang hidup dalam dunia virtual. Hal ini sesungguhnya bukan hal yang asing dalam pelayanan rohani di era teknologi media. Subowo menyatakan bahwa unsur sakral tidak lagi menjadi fokus dalam ruang nyata namun juga ruang virtual(Subowo, 2021). Sedangkan Evans menuliskan bahwa pelayanan Ilahi yang aktual tidak lagi fokus dalam ruangan namun telah menuju dunia digital(Siahaan, 2017). Penelitian Mick sudah menunjuk kepada realitas digital native yang telah memaksa konsep pemulihan diri berjumpa dengan Tuhan yang tidak lagi terbatas hanya dalam fisik namun secara virtual(Sopacoly \& Lattu, 2020). Gereja bertanggung jawab untuk melatih dan memuridkan serta endorse pewarta dan penginjil baru dari orang awam khusus dalam media virtual. Praktisi gereja harus rendah hati dan mempunyai beban yang disertai dengan tanggung-jawab dan disiplin yang tinggi untuk mengajar, melatih, memuridkan serta mendampingi para Influencer Kristen ini dalam peran misi dan penginjilan dengan kualitas yang tinggi. Sejalan dengan peneletian Saptono bahwa dalam perspektif historis-teologis, penginjilan mempunyai pengaruh yang besar bagi pertumbuhan gereja. Oleh karena itu, tinggi rendahnya penginjilan yang dilakukan gereja selalu menjadi indikator bertumbuh tidaknya gereja. Sebab penginjilan akan mendorong pertumbuhan gereja. Sedangkan gereja yang bertumbuh tentu akan melakukan penginjilan (Saptono, 2019). Intinya, misi 
dan penginjilan adalan nafas kehidupan panggilan gereja yang diteruskan lewat media dan influencer Rohani.

Influencer Kristen melaksanakan perwujudan Misi Amanat Agung. Karena dampak manfaat kebenaran Firman adalah bahwa seseorang siap untuk berubah menuju kehidupan rohani. Target kelanjutannya adalah pemuridan dalam ruang virtual. Alkitab menuliskan bagaimana perkataan Yesus yang adalah Firman sanggup menyembuhkan baik seorang anak yang kerasukan (Matius 15: 21-28) dan seorang hamba dari perwira Romawi yang disembuhkan Yesus secara virtual (Lukas 7: 1-10). Pewarta Firman Tuhan tidak harus Pendeta atau Gembala dalam virtual. Namun bisa siapa saja yang terbeban dan punya kualitas. Bisa juga dilakukan kombinasi untuk lebih menarik. Pewartaan Firman harus berbeda dengan konsep umum dalam gereja, seperti ruang tanpa panggung, rileks dan bersahabat serta suasana yang studio yang dibuat konsep milenial. Momentum penting dalam menjangkau digital native adalah melakukan pendekatan dengan karakteristik yang mereka miliki. Strategi pewartaan Injil setidaknya harus memenuhi unsur [1] harus bersumber dari Alkitab,[2] disampaikan oleh seseorang yang memang dipersiapkan untuk itu,[3] ada orang orang yang mendengar secara langsung, dan [4] harus memberikan nilai nilai kebahagian, kekuatan dan penghiburan(Lontoh, 2016). Strategi lainnya adalah pewartaan dengan tema-tema kekinian kepada generasi milenial. Perhatian utama adalah kepada isu sentral yang terbaru dengan prinsip persiapan iman dan harapan eskatologis masa depan. Generasi ini meninggalkan gereja karena tema tidak menarik, tidak bisa dipraktekkan dalam hidup dan tidak menyentuh kebutuhan terdalam. Pemberitaan harus menyatakan penghargaan dan kasih sayang Tuhan kepada mereka. Ada contoh kongkrit dan bisa mempergunakan kesaksian-kesaksian dari berbagai sumber. Hal ini menjawab kemarahan dan ketidakpedulian generasi ini karena disepelekan. Kondisi mereka memang sangat berbeda dengan generasi yang diatasnya(Handi Irawan D, 2018).

Fleksibilitas dari Influencer Kristen adalah memposisikan dirinya sebagai seorang sahabat bukan pengkotbah, jangan mencoba untuk menjadi pengajar namun jadilah seorang yang selalu membangun hubungan. Penelitian Kosma tentang hubungan pertemanan adalah sebagai komunitas ilahi yang melaluinya orang percaya mendapatkan kekuatan dan peneguhan sehingga berdampak bagi Kerajaan Allah(Manurung, 2021). Relasi persahabatan memudahkan pemilihan kata yang ringan, 
penampilan yang terkesan santai tidak formal, setting tempat yang sederhana tanpa panggung dan lepas dari aksesori gereja memberi keleluasan tersendiri, menghilangkan kesan kaku dan asing. Pewartaan kabar baik diusahakan tidak menyentuh kepada permasalahan doktrin seperti baptisan, Perjamuan Kudus, eskatologi dan lain-lain. Tetapi kepada tema tentang kehidupan benar, keselamatan, pengharapan, kekuatan iman dalam pergumulan, menjadi pribadi yang benar, mengandalkan Tuhan dan lain sebagainya. Penulis memberikan alternatif fleksibilitas seperti solusi singkat dan sederhana atas pertanyaan yang sebenarnya ditanyakan orang di komunitas Anda. Jawaban atas pertanyaan ketika orang ada di moment terendah berkaitan dengan kebenaran. Sebagai contoh pernikahan, sex, obat, pergaulan, games, pendidikan dan sebagainya. Mulailah berinovasi dalam strategi mereka yaitu dengan menyesuaikan konten agar sesuai dengan durasi video di berbagai stage yang menarik.

Tentu pribadi influencer sebagai pembawa firman itu sendiri sangat menentukan. Hendaknya influencer Kristen ini berada dalam penggembalaan yang jelas dengan kehidupan baru yang terus bertumbuh selain belajar tentang komunikasi publik dalam ruang media. Standar kehidupan kristiani sangat ditekankan. Baik itu dari kehidupan pribadi, komunitas yang diikuti dan kegiatan kegiatan yang dilihat oleh banyak orang dan diliput oleh media. Sudah sebuah keharusan standart Alkitab menjadi ukuran dari seorang pewarta kabar baik dalam media sosial ini. Kualitas dijaga dengan monitoring dan evaluasi dari berbagai pihak seperti contoh gereja dan gembala.

Dalam hasil survey Barna yang dibuat dalam kemitraan dengan Seed Company pada tahun 2018 menunjukkan bahwa, hanya 17 persen pengunjung gereja yang pernah mendengar tentang "Amanat Agung” dan tahu apa arti istilah itu. Sisa dari pengunjung gereja sebagian besar belum pernah mendengarnya (51\%), dengan seperempat (25\%) mengatakan bahwa mereka pernah mendengarnya tetapi tidak dapat mengingat arti pastinya. 


\section{Figure 1.}

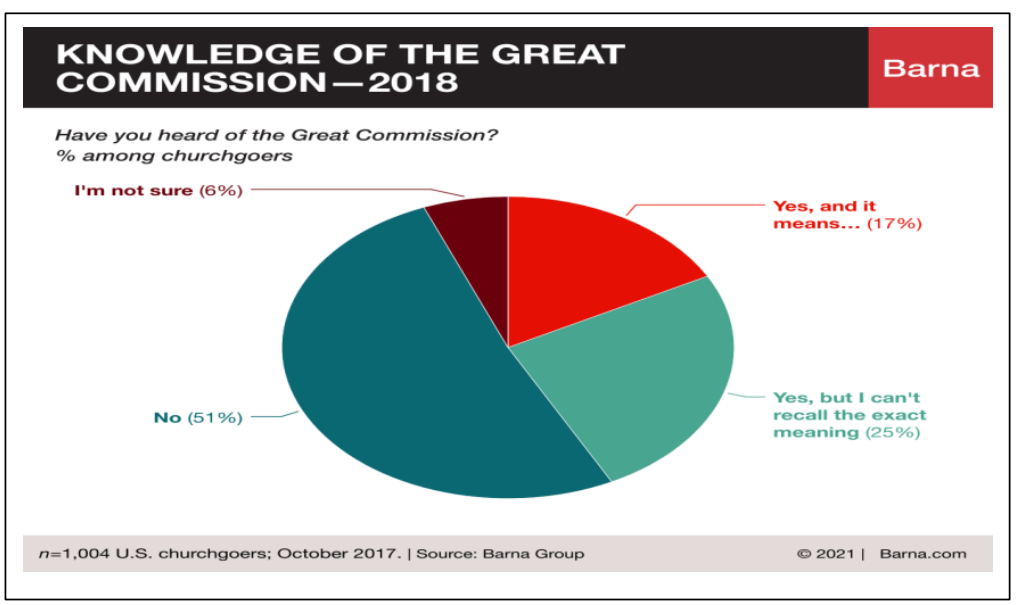

Gambar di atas menunjukkan survey Barna bagaimana generasi muda-Milenial dan Gen Z-memikirkan dan mempraktikkan penginjilan secara berbeda dari orang Kristen yang lebih tua, dengan persentase yang signifikan dari mempraktekkan Milenial Kristen yang secara khusus menentang penginjilan(Kinnaman, 2021). Meski begitu, ketika kaum muda memang ingin membagikan iman mereka kepada orang lain, gereja lokal tampaknya menjadi mitra dalam upaya ini. Persepsi orang Kristen tentang misi memang berubah, terutama ketika generasi muda merenungkan seperti apa misi global dan upaya penginjilan dalam istilah mereka. Data ini harus bertindak sebagai pengingat bagi para pemimpin gereja untuk mempertimbangkan bagaimana mereka mendefinisikan dan mempertahankan budaya misi yang sehat dan efektif melalui gereja mereka dan lintas generasi.(Kinnaman, 2021) Dari data di atas menunjukkan peran besar dan penting bahwa influencer Kristen menjadi misonari Allah dalam dunia digital untuk mengajarkan, menggambarkan dan menyatakan kasih dan keselamatan kekal.

\section{Membangkitkan Influencer dalam Kapasitas Pelayanan Ilahi}

Generasi digital mempunyai kecenderungan tertutup, independen dan tidak bergantung kepada lainnya namun menghargai perbedaan yang ada dan sangat pragmatis dalam menyelesaikan permasalahan yang ada(Suci Prasasti, 2020). Sangat penting untuk influencer melihat karakteristik khas sebagai strategi pendekatan komunikasi dan hubungan. Selain pendekatan yang tidak boleh dilupakan adalah influencer dapat menjadi public figure, dikarenakan secara psikologi mereka memiliki tokoh sentral menjadi panutan, pujaan dan kebanggaan seperti contoh para selegram di 
dunia digital(Subowo, 2021) Data penduduk Indonesia menggunakan media sosial 98,2\% lewat smart phone dan 74,7\% dengap laptop. Durasi penggunaan media sosial sendiri berkisar 3 jam 14 menit (Kemp, 2021). Table di bawah menjadi data konten dan media yang menjadi fokus metode platform(Kemp, 2021).

Table 1. Platform Terpopuler di Indonesia 2021

\begin{tabular}{lll} 
No. & Platforms & Procentase \\
\cline { 2 - 3 } 1. & Youtube & $91,8 \%$ \\
2. & Whatsapp & $87,7 \%$ \\
3. & Instagram & $86,6 \%$ \\
4. & Facebook & $85,5 \%$ \\
5. & Twitter & $63,6 \%$ \\
6. & Facebook Messanger & $52,4 \%$ \\
7. & Line & $44,3 \%$ \\
8. & Linkelin & $39,4 \%$ \\
9, & TikTok & $38,7 \%$ \\
10. & Pinterest & $35,6 \%$
\end{tabular}

Musik dan narasi yang berbentuk video online sangat tinggi digunakan sebesar 98,5\%, sedangkan video bloggings (vlogs) sendiri mendekati angka 74,3\%. Media hanya dengan audio musik streaming sebesar $84 \%$. Dari data ini konten yang dibuat sangat terbuka lebar dalam memberikan kontribusi musik gerejawi dengan narasi Firman setiap hari untuk followernya. Pada intinya semua jenis media sosial dapat digunakan oleh influencer Kristen namun fokuskan kepada jumlah pengguna terbanyak yaitu platform Youtube, Instagram, Facebook dan TikTok yang memberikan kemudahan siaran langsung.

Menjaga kualitas Influencer Kristen menjadi hal yang tidak dapat dilupakan begitu saja. Langkah-langkah untuk membentuk influencer rohani dalam media sosial memerlukan strategi khusus. Hal penting adalah influencer Kristen diusahakan sebaik mungkin mempunyai kemampuan untuk berapologetika dalam ruang virtual. Meskipun tidak seperti debat dan diskusi seperti dalam kelas atau seminar, namun peran mereka sebagai perpanjangan pelayanan gereja dalam ruang publik menuntut kesiapan jawaban dan pertahankan nilai kebenaran itu sendiri. Senada dengan Sitepu menyatakan ada 
korelasi yang kuat bagi perkembangan intelektualitas dan spiritualitas ketika seseorang berapologetika. Hal ini disebabkan karena apologetika mendorong seseorang mendalami Kitab Suci dan belajar untuk memahami, membahasakan, dan melakukannya (Sitepu, 2020). Langkah persiapan itu seperti, pertama dengan menyediakan hamba Tuhan yang terbeban untuk melatih mereka dalam pembentukan team dan membuka kelas mentoring khusus. Pengertian dasar Alkitab dan hermeneutic yang benar membuka wawasan dan pemahaman baru. Hal lainnya adalah bagaimana belajar kepekaan mendengar suara Tuhan yang dibangun dalam kontemplasi setiap waktu. Hal kedua bagaimana gereja membuka peluang, mendukung dan memberikan mandat kepada Influencer Kristen sebagai misionari digital untuk masuk dan mengambil inisiatif penetrasi kepada genenerasi ini secara lebih masif dan konstruktif. Gereja jangan sampai menekan dan meremehkan pelayanan mereka dalam ruang digital yang memungkinkan sangat berbeda model. Gereja harus dapat mengantisipasi paradigma tradisional khususnya di kalangan baby boomers dan Generasi $\mathrm{X}$ bahwa sosial media identik dengan dunia dan dosa. Gereja harus menjadi promotor untuk menolong dan menginisiasi influencer Kristen agar dimunculkan lebih cepat seturut dengan perkembangan media sosial di era Society 5.0. Hal ketiga adalah menciptakan tandem penetrasi yang kuat dalam misi dan penjangkauan. Perpaduan antara gereja dengan influencer Kristen sebagai misionari dunia digital. Semua elemen berkolaborasi maksimal dalam menggunakan media sosial bagi Kristus. Bukan saja diperlukan banyak biaya yang relative besar untuk jangka panjang namun juga misi dan visi yang kuat dalam program. Gereja harus keluar dari dinding persegi empat sedangkan influencer Kristen terus beselancar dengan ide kreativitas kekinian dalam menjalankan misi penginjilan baik di dunia nyata maupun virtual.

\section{SIMPULAN}

Native Digital merupakan komunitas dengan komposisi jumlah jiwa terbesar sebagai target misi dan penjangkauan. Kebebasan berekspresi dengan konten rohani dalam media sosial memberi kesempatan untuk mengabarkan kabar baik kepada generasi digital khususnya. Gereja dan penatalayanannya tidak pernah menjadi maksimal dalam pelayanan tatap muka tradisional. Dalam kondisi kekinian gereja harus keluar dari pola lama dengan strategi baru yaitu melahirkan para influencer Kristen dalam ruang digital. Mereka sudah seharusnya menjadi perpanjangan tangan pelayanan 
gereja sebagai misionaris ruang media, penetrasi dan berkecimpung secara aktif melayani generasi native digital. Gereja harus dapat bekerja sama dan bertanggung jawab dengan influencer Kristen khususnya dalam Misi dan Penginjilan, sehingga dapat menjangkau lebih banyak jiwa dari generasi native digital untuk diselamatkan.

Penelitian ini memiliki keterbatasan tentang strategi untuk menggembalakan digital native sehingga terbuka kesempatan untuk penelitian lanjutan.

\section{DAFTAR PUSTAKA}

Afandi, Y. (2018). Gereja Dan Pengaruh Teknologi Informasi "Digital Ecclesiology." Fidei: Jurnal Teologi Sistematika Dan Praktika, 1(2), 270-283. https://doi.org/[https://doi.org/10.34081/fidei.v1i2.12]

Ahmad, A. (2020). Media Sosial dan Tantangan Masa Depan Generasi Milenial. Avant Garde, 8(2), 134-148. https://doi.org/https://doi.org/10.36080/ag.v8i2.1158

Anjani, S., \& Irwansyah, I. (2020). Peranan Influencer Dalam Mengkomunikasikan Pesan Di Media Sosial Instagram [the Role of Social Media Influencers in Communicating Messages Using Instagram]. Polyglot: Jurnal Ilmiah, 16(2), 203229. https://doi.org/https://doi.org/10.19166/pji.v16i2.1929

Camerling, Y. F., Lauled, M. C., \& Eunike, S. C. (2020). Gereja Bermisi Melalui Media Digital Di Era Revolusi Industri 4.0. Visio Dei: Jurnal Teologi Kristen, 2(1), 1-22. https://doi.org/10.35909/visiodei.v2i1.68

Diana, R. (2019). Peran Komunikator Kristen Dalam Strategi Pekabaran Injil Di Era Revolusi Industri 4.0. Integritas: Jurnal Teologi, 1(1), 66-73. https://doi.org/10.47628/ijt.v1i1.3

Dwiraharjo, S. (2020). Konstruksi Teologis Gereja Digital: Sebuah Refleksi Biblis Ibadah Online di Masa Pandemi Covid-19. Epigraphe: Jurnal Teologi Dan Pelayanan Kristiani, 4(1), 1-17. https://doi.org/[https://doi.org10.33991/epigraphe.v4i1.145]

Ezzat, H. (2020). Social media influencers and the online identity of Egyptian youth (Universitat Rovira i Virgili; Vol. 12). Universitat Rovira i Virgili. https://doi.org/https://doi.org/10.1386/cjcs_00017_1

Garcia-Roca, A. (2020). Spanish Reading Influencers In Goodreads: Participation, Experience and Canon Proposed. Jurnal Of New Aproaches In Educational Research, 9(2), 153-166. https://doi.org/hhtps://doi.or/10.7821/naer.2020.7.453

Handi Irawan D, C. A. P. (2018). Gereja Sudah Tidak Menarik Bagi Kaum Muda, [The Church Is Not Attractive To Young People].

Irawan, H. (2021). Spiritualitas Umat Kristen Indonesia 2021.

Kemp, S. (2021). Digital 2021 : Indonesia.

Kinnaman, D. (2021). Missions in Review_-Trends Impacting Global Missions \& Evangelism.

Lilo, D. D. (2020). Misi Gereja : Menjangkau Yang Tidak Terjangkau di Era dan Pasca Pandemi Covid-19. Phronesis, 3(2), 204-217.

Lontoh, F. O. (2016). Pengaruh Kotbah, Musik Gereja dan Fasilitas Gereja Terhadap Tingkat kehadiran JemaatChristian. Kerusso, 1(1), 1-15.

Manuel Rueda. (2019). Bible-Preaching Priest Becomes Social Media Star. 
Manurung, K. (2021). Alkitab Dan Hubungan Pertemanan Kajian Teologi Pentakosta Memaknai Hubungan Pertemanan Dalam Alkitab. VOX DEI: Jurnal Teologi Dan Pastoral , 2(1), 31-49. https://doi.org/10.46408/vxd.v2i1.35

Marc Prensky. (2001). Digital Natives, Digital Immigrants. On the Horizon, 9(5), 1-6. https://doi.org/https://doi.org/10.1177/1461444818783102

McCorquodale, C. (2021). New directions in youth and young adult ministry leadership: Where have we been and more importantly where are we headed? Religions, 12(3), 1-10. https://doi.org/10.3390/rel12030146

Mulawarman, \& Nurfitri, A. D. (2017). Perilaku Pengguna Media Sosial beserta Implikasinya Ditinjau dari Perspektif Psikologi Sosial Terapan. Buletin Psikologi, 25(1), 36-44. https://doi.org/10.22146/buletinpsikologi.22759

Negoita, A. G. (2019). Religiosity In The Contemporary World. Euromentor, X(3), 2738.

Rumbiak, A. K. (2020). Teologi Ibadah dan Spiritualitas Generasi Milenial. Amreta, $3(2), 64-100$.

Saptono, Y. J. (2019). Pentingnya Penginjilan dalam Pertumbuhan Gereja. DIEGESIS: Jurnal Teologi Kharismatika, 2(1), 12-24.

Siahaan, H. E. R. (2017). Aktualisasi Pelayanan Karunia di Era Digital. Epigraphe: Jurnal Teologi Dan Pelayanan Kristiani, 1(1), 23-38. https://doi.org/https://doi.org/10.33991/epigraphe.v1i1.7

Sitepu, N. (2020). Relasi Intelektualitas Dan Spiritualitas Dalam Berapologetika: Suatu Tinjauan Injili. VOX DEI: Jurnal Teologi Dan Pastoral , 1(2), 118-130. https://doi.org/10.46408/vxd.v1i2.36

Sopacoly, M. M., \& Lattu, I. Y. M. (2020). Kekristenan dan Spiritualitas Online: Cybertheology sebagai Sumbangsih Berteologi di Indonesia. Gema Teologika : Jurnal Teologi Kontekstual Dan Filsafat Keilahian, 5(2), 137-154. https://doi.org/10.21460/gema.2020.52.604

Soukup, P., \& Glader, P. (2020). A debate between Paul Soukup, SJ and Paul Glader on how digital culture is affecting media education on religion. Church, Communication and Culture, 5(2), 145-156. https://doi.org/https://doi.org/10.1080/23753234.2020.1765698

Subowo, A. T. (2021). Membangun Spiritualitas Digital bagi Generasi Z, [Building Digital Spirituality for Generation Z]. Dunamis, 5(2), 379-395. https://doi.org/https://doi.org/10.30648/dun.v5i2.464

Suci Prasasti, E. T. P. (2020). Karakter dan Perilaku Milenial: Peluang atau Ancaman Bonus Demografi. Consilia, 3(1), 10-22.

Supratman, L. P. (2018). Penggunaan Media Sosial oleh Digital Native, [Use of Social Media by Digital Native]. Jurnal Ilmu Komunikasi, 15(1), 47-60. https://doi.org/https://doi.org/10.24002/jik.v15i1.1243

Toatubun, H. (2021). Influencer Rohani Milenial, Ps Raditya Oloan Pangabean Tutup Usia.

William Glanz. (2018). Music and Social Media: in Perfect Harmony.

Zaluchu, S. E. (2019). Spiritual Kristiani di Tengah Laju Peradaban Digital. Merajut Keragaman Untuk Mencapai Kesejahteraan Psikologis Dalam Konteks Masyarakat 5.0, 198-2019.

Zaluchu, S. E. (2020b). Strategi Penelitian Kualitatif dan Kuantitatif Di Dalam Penelitian Agama. Evangelikal: Jurnal Teologi Injili Dan Pembinaan Warga Jemaat, 4(1), 28. https://doi.org/10.46445/ejti.v4i1.167 